\section{$\underset{\substack{\text { hommes } \\ \text { \& migrations }}}{ }$}

\section{Hommes \& migrations}

Revue française de référence sur les dynamiques

migratoires

$1296 \mid 2012$

Le Mexique dans les migrations internationales

\title{
Boualem Sansal, Rue Darwin
}

Gallimard, 2011, 255 pages, 17,50 euros

\section{Mustapha Harzoune}

\section{(2) OpenEdition}

1 Journals

\section{Édition électronique}

URL : http://journals.openedition.org/hommesmigrations/1536

DOI : 10.4000/hommesmigrations. 1536

ISSN : 2262-3353

\section{Éditeur}

Musée national de l'histoire de l'immigration

\section{Édition imprimée}

Date de publication : 1 mars 2012

Pagination : 154-155

ISSN : 1142-852X

\section{Référence électronique}

Mustapha Harzoune, «Boualem Sansal, Rue Darwin », Hommes \& migrations [En ligne], 1296 | 2012, mis en ligne le 19 juin 2013, consulté le 22 septembre 2020. URL : http://journals.openedition.org/ hommesmigrations/1536; DOI : https://doi.org/10.4000/hommesmigrations.1536

Ce document a été généré automatiquement le 22 septembre 2020.

Tous droits réservés 


\title{
Boualem Sansal, Rue Darwin
}

\author{
Gallimard, 2011, 255 pages, 17,50 euros
}

\author{
Mustapha Harzoune
}

\section{RÉFÉRENCE}

Boualem Sansal, Rue Darwin, Gallimard, 2011, 255 pages, 17,50 euros

1 Rue Darwin interpelle davantage l'Algérie que la société française. Du moins, pourraiton le croire. Car, à bien lire, les questions migratoires et mémorielles, comme la question du lien entre les deux pays parcourent aussi le nouveau roman de Sansal. Ce texte allégorique évoque l'Histoire récente et troublée, la quête des origines, la mémoire ("Il n'y a pas d'oubli sans une vraie mémoire des choses") et les identités. Ici, elles “ ne s'additionnent pas, elles se dominent. Et se détruisent". Le récit s'ouvre dans un hôpital parisien où Karima invite son fils Yazid, le narrateur, à retourner du côté de l'enfance, dans la rue Darwin justement, sise à Belcourt, quartier populaire d'Alger. Il y dénichera quelques secrets de famille. Le rejeton n'ignore pas qu' il n'est vraiment pas bon de vivre avec ses propres secrets, il faut les percer ou mourir". Pour ne pas "mourir", Yazid remonte le fil d'une existence incroyable : faite d'adoption, d'enlèvement et de mère substituée. Tout commence dans un bordel et se poursuit à Alger en 1957. Massu, Bigeard et Aussaresses ne rigolaient pas à l'époque, et les Algériens encore moins ! Yazid a alors 8 ans, une double histoire, une double vie, une double amputation commencent. C'est ce puzzle existentiel que Karima demande à son fils de reconstituer. Pourtant, toute sa vie, il s'est appliqué justement à ne pas en restituer l'ensemble. Il faut dire que l'exhortation maternelle va conduire Yazid à manipuler de la dynamite. Une dynamite nourrie de trahison, de reniement, de mensonge, de honte et du "regret violent de ne pas avoir vécu la vie qui aurait dû être la mienne". Tout cela fut "irréconciliable. C'était une famille ou l'autre [...] deux mondes que tout séparait, et la vérité qui pouvait les réconcilier en moi était inaccessible [...]. Jusqu'à la fin je resterais au milieu du gué. La dernière qui pouvait me sauver, maman, se mourrait à l'hôpital". Mais voilà, "en refusant ma vérité, en niant une partie de moi sans accepter clairement l'autre, je me suis enfermé dans l'ambiguïté,j'ai fini par n'être rien, un 
être trouble et inconsistant sans avenir parce que sans passé et coupé de son présent". L'histoire collective n'est jamais loin des pérégrinations individuelles. L'Algérie est là, dans la verve torrentielle de Sansal qui emporte tout sur son passage, désacralise l'Histoire et déboulonne les tartuffes. Il montre avec une efficacité de gâchette professionnelle que la société algérienne, après avoir été colonisée, a été, depuis l'indépendance - "le début d'un vaste malheur" écrit-il -, militarisée, emprisonnée, martyrisée, boumédiènisée, paupérisée, bureaucratisée, fatiguée, trabendisée, sinisée, islamisée, alzheimerisée, embobinée, pigeonnée, mystifiée, arabisée, moudjahidinisée... À la clef, Yazid, qui n'est pas au bout de ses surprises, se demande : “Je n'ignore pas seulement mes origines, qui est mon père et qui est ma mère, qui sont mes frères et mes sœurs, mais aussi quel monde est ma terre et quelle véritable histoire a nourri mon esprit. "De ce côtéci de la Méditerranée, Rue Darwin devrait aussi interpeller. Notamment en revisitant le passé, la guerre d'Algérie, et surtout offrir l'occasion de s'interroger sur ce qu'il en est advenu depuis. Sansal écrit que la question n'est pas de savoir si la France et l'Algérie “ se détestent, ça ne compte pas, ils font bien des affaires ensemble, mais les deux ont failli à l'honneur, dans la guerre comme dans la paix, et la honte est une gangrène, elle ne guérit pas, se propage, si bien qu'il faut couper toujours plus haut et qu'un jour nous serons forcés de trancher à la gorge pour nous guérir du pêché originel". Et d'ajouter : "Aucune réconciliation, aucune repentance, aucun raité, n'y changerait rien, la finalité des guerres n'est pas de chialer en se frappant la poitrine et de se répandre en procès au pied du totem, mais de construire une paix meilleure pour tous et de la vivre ensemble." Voilà! Il ne reste plus qu'à demander le programme ! C'est du côté d'Alexis Jenni dans L'Art français de la guerre que le lecteur le trouvera. Dans cet hôpital parisien, la diaspora algérienne se retrouve autour de la figure maternelle et peut être nationale. Alitée, mal en point, mourante. La fratrie mondialisée de Yazid est réunie. Il y a là Karim (le Marseillais), Nazim (l'homme d'affaires parisien), Souad (l'universitaire américaine) et Mounia (consultante en communication au Canada). Seul manque Hédi, le cadet. Enfant de "la Matrice", entendre l'école algérienne, il serait occupé au Waziristân, à rêver d'un monde aux couleurs plus verdoyantes. 